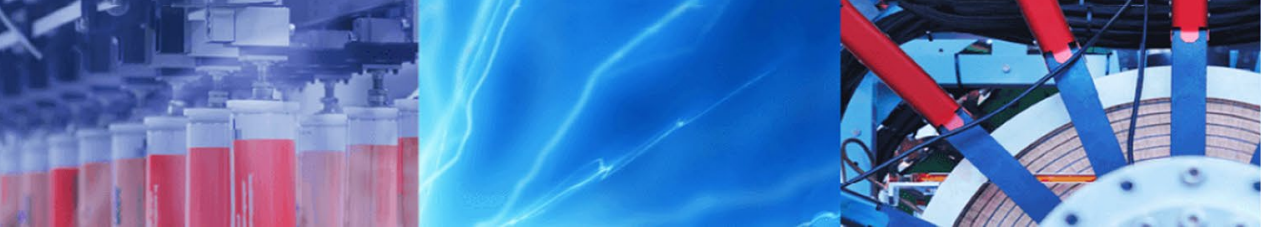

Research Article

\title{
Biofouling inhibition for aquaculture cage nets through a coating nano zinc and silicon oxides incorporated with polyaniline
}

\author{
N. Manju Lekshmi ${ }^{1}$ - P. Muhamed Ashraf ${ }^{1}$ (D) A. K. Keerthana ${ }^{1} \cdot$ Saly N. Thomas ${ }^{1} \cdot$ Leela Edwin $^{1}$
}

Received: 10 June 2020 / Accepted: 29 October 2020 / Published online: 20 November 2020

(c) Springer Nature Switzerland AG 2020

\begin{abstract}
Biofouling is one of the problems faced by cage aquaculture farmers, and its management is expensive. In this present study, polyethylene aquaculture cage nets were coated with the nano structured oxides of zinc and silicon incorporated with polyaniline. Fourier transform infrared spectroscopy and scanning electron microscope data evidenced that a thick coating of nano particle was formed on polyethylene. The oxides were attached to the quinoid part of polyaniline. The antifouling efficiency of treated cage net was tested by exposing in the Cochin estuary for three months. A webbing treated with $0.01 \%$ of each of the nano zinc oxide $(\mathrm{ZnO})$ and silicon dioxide $\left(\mathrm{SiO}_{2}\right)$ exhibited the highest biofouling resistance. Reinforcement of nano $\mathrm{SiO}_{2}$ with $\mathrm{ZnO}$ increased biofouling resistance as the former complemented the coating to make the system more efficient.
\end{abstract}

Keywords Biofouling $\cdot$ Cage aquaculture $\cdot$ Polyaniline $\cdot$ Polyethylene $\cdot$ Nano zno $\cdot \mathrm{Nano} \mathrm{sio}_{2}$

\section{Introduction}

In India, cage aquaculture is an emerging sector, and is growing synchronously with some problems such as a deficiency of good quality seed and feed, and biofouling. The fouling of cage nets by organisms including bacteria, algae, mollusc, bivalves, and crustaceans, increases the maintenance cost, pollutant accumulation (organic loads and nutrients) leading to eutrophication, and the lack of oxygen in culture systems. This problem eventually results in drastic ecological and economic implications [1]. Biofouling is a serious problem in aquacutlture because its management utilizes one fourth of total project expenses $[2,3]$.

Voluminous antifouling compounds and strategies are available globally, but many of these compounds cause environmental problems and influence non target organisms. Copper based biocides are highly effective against many foulers; however the effects of copper in aquatic systems are not widely known, and many algal foulers are copper resistant species and cannot be controlled [4]. The current antifouling strategies used under the marine environment are ineffectual and the development of competent technologies to prevent biofouling in the aquatic environment is required urgently [3].

High density polyethylene (PE) fibers are generally used to fabricate aquaculture cage nets. PE is a non polar molecule and very difficult to coat any antifouling biocides directly over it. Ashraf et al. [5] devised a coating method to coat polyaniline (PANI) over PE webbings. Moreover nano copper oxide has been coated on PANI, which provided an excellent biofouling resistance and it was explained due to the generation of hypochlorous acid [5, 6]. Nano technology and nano materials facilitated the exploration of biocides with high efficacy and low requirement of chemicals. Nano copper oxide coating on PANI [5] and nano copper

P. Muhamed Ashraf, ashrafp2008@gmail.com; N. Manju Lekshmi, manjuaem@gmail.com; A. K. Keerthana, keerthanaak5050@gmail.com; Saly N. Thomas, salynthomas@gmail.com; Leela Edwin, leelaedwin@gmail.com | 'ICAR Central Institute of Fisheries Technology, Matsyapuri PO, Cochin 682029, India. 
oxide reinforced hydrogel coating on PE exhibited excellent biofouling resistance [6]. Although copper oxide is a micro nutrient, stakeholders do not use it because of regulatory restrictions. Mohan and Ashraf [7] synthesized nano silicon dioxide incorporated mixed charged zwitterionic hydrogel and demonstrated an improved biofouling resistance of aquaculture cagenet under the marine environment. Coating of nano silica functionalised zwitterionic sulfobetaine exhibited increased wettability, microorganism inhibition and decreased serum albumin protein fouling [8]. Nano $\mathrm{SiO}_{2}$ is considered an ecologically affable oxide and extensively used to incorporate as antibacterial agents [9]. $\mathrm{SiO}_{2}$-polystyrene-N-halamine nano particles used to destroy Escherichia coli (E. coli) cell surfaces. The $\mathrm{SiO}_{2}$ acted as a carrier and also improved the actvity of N-halamine [9]. Zwitterionic polymer-coated $\mathrm{Si}_{x} \mathrm{~N}_{4}$ surfaces exposed to a fibrinogen solution inhibited protein [10]. The coating of mesoporous silica on indium tin oxide electrode acted as molecular sieve and prevented the accumulation of haemoglobin during the detection of propranolol [11]. $\mathrm{SiO}_{2}$ incorporated matrices described above increased the antibacterial, fouling and protein inhibition efficiency.

Nano $\mathrm{ZnO}$ exhibits anti-microbial and antifouling properties. Al-Naamani et al. [12] synthesized chitosan- nano $\mathrm{ZnO}$ composite exhibiting diatom and bacterial resistance under the marine environment. Zhang et al. [13] fabricated super hydrophilic and hydrophobic surfaces by coating textured super hydrophobic nano $\mathrm{ZnO}$ on polydimethylsiloxane film, and the surface inhibited the oil accumulation. Nano $\mathrm{ZnO}$ rods were incorporated in the polyethersulfone membrane to improve the morphology, hydrophilicity and biofouling resistance [14]. A nano $\mathrm{ZnO}$ reinforced polysufone membrane exhibited excellent hydrophilicity, water permeability, increased porosity, and rejection of organic molecule adsorption implying its antifouling property [15].

Nano mixtures having different properties coated over steel exhibited improved corrosion resistance [16] and few studies have been conducted using the nano materials of different properties in a mixture to prevent biofouling. Nano $\mathrm{SiO}_{2}$ and $\mathrm{ZnO}$ are considered safe, due to their toxicity characteristics and environmental friendliness. Nano $\mathrm{ZnO}$ deterred microorganisms through photocatalytic activity by forming $\mathrm{OH}$ radical $(\mathrm{OH})$ by reacting with water [17]. The study on penetration of UV visible solar radiation in the oceanic waters revealed that $30-40 \%$ deeper penetration than predicted euphotic zone. The UVA $(315-380 \mathrm{~nm})$ radiation penetrate about 5-7 m deep in an oligotrophic water of depth having 50-70 $\mathrm{m}$ [18]. The electron rich materials like reduced graphene, nano composites of semiconductors, and carbon nano tubes were used to reduce the band gap of $\mathrm{TiO}_{2}$ and $\mathrm{ZnO}$. This improved the photocatalytic effect of the above materials
[19-23]. In the present study $\mathrm{ZnO}$ is coated over electron rich PANI and this may improve photocatalytic effect of $\mathrm{ZnO}$. Coating of nano $\mathrm{SiO}_{2}$ and $\mathrm{ZnO}$ on an electron rich PANI may increase the antibacterial and biofouling resistance. Similar works are considerably limited especially in the development of strategies for preventing biofouling. A two step process was employed in this study instead of PANI-ZnO- $\mathrm{SiO}_{2}$ composite coating over PE since the latter exhibited poor biofouling inhibition due to the utilisation of all electronic states of $\mathrm{ZnO}$ and $\mathrm{SiO}_{2}$ for forming the composite. The study aimed to coat nano $\mathrm{SiO}_{2}$ and $\mathrm{ZnO}$ mixture of varied concentrations on PANI treated PE aquaculture cage net and to test its biofouling resistance.

\section{Material and methods}

Polyethylene (PE) aquaculture cage net, a material frequently used in cage aquaculture, was purchased with $1 \times 3$ ply and a mesh size of $25 \mathrm{~mm}$ procured from Matsyafed Net Factory, Cochin, India. Colored PE netting was used for the experiment since farmers prefer colored nettings. Aniline, ammonium persulphate, and $\mathrm{HCl}$ were purchased from $\mathrm{CDH}$, India. Nano $\mathrm{ZnO}$ and hydrophilic nano $\mathrm{SiO}_{2}$ were purchased from Reinste Nano ventures, India. The size, specific surface area and purity of nano $\mathrm{ZnO}$ was $14 \mathrm{~nm}, 30 \pm 5 \mathrm{~m}^{2} / \mathrm{g}$ and $99 \%$ respectively. Size, specifc area, bulk density and purity of hydrophilic nano $\mathrm{SiO}_{2}$ was 7-14 $\mathrm{nm},>200 \mathrm{~m}^{2} \mathrm{~g}^{-1}, 0.048 \mathrm{~g} \mathrm{~cm}^{-2}$ and $99.8 \%$ respectively.

Polyaniline (PANI) was synthesised in situ on PE aquaculture cage nets by following the procedure provided by Ashraf et al.[5]. The surface activation of the PE cage net was carried out by immersing the net overnight in acidified aniline $(0.3 \mathrm{M}$ in $0.1 \mathrm{M} \mathrm{HCl})$ solution and the following day ammonium persulfate $(0.3 \mathrm{M}$ in $0.1 \mathrm{M} \mathrm{HCl})$ was added dropwise along the sides of container without disturbing the container. This will enable the formation of nano sized and rod shaped PANI over the net. Kept the reaction mixture overnight, and the following day the net samples were taken out, allowed to dry in air. Excess PANI was removed by washing with water. The PANI coated polyethylene (PE-PANI) aquaculture cage nets were immersed overnight in varied concentrations of aqueous nano $\mathrm{ZnO}$ and $\mathrm{SiO}_{2}$ mixtures (Table 1). On subsequent day, samples were taken out and air dried. This step will enable the nano materials to adsorb over the PANI. Pre-weighed, and tagged treated nets were tied in a PVC frame and immersed in the test site at Cochin estuary, $1 \mathrm{~m}$ below the low tide height for 3 months. The samples were retrieved once in every month for evaluating their fouling resistance through biomass accumulation and microscopic studies. The retrieved samples were cleaned by running water, 
Table.1 Different treatments used for the experiment

\begin{tabular}{ll}
\hline Treatment & Details of treatment \\
\hline S0 & Untreated Polyethylene(PE) \\
S1 & Polyaniline treated PE (PE-PANI) \\
S2 & PE PANI $+0.01 \%(w / v) \mathrm{SiO}_{2}$ \\
S3 & PE PANI $+0.02 \%(w / v) \mathrm{SiO}_{2}$ \\
S4 & PE PANI $+0.01 \%(w / v) \mathrm{SiO}_{2}+0.01 \%(w / v) \mathrm{ZnO}$ \\
S5 & PE PANI $+0.02 \%(w / v) \mathrm{SiO}_{2}+0.01 \%(w / v) \mathrm{ZnO}$ \\
S6 & PE PANI $+0.01 \%(w / v) \mathrm{SiO}_{2}+0.02 \%(w / v) \mathrm{ZnO}$ \\
S7 & PE PANI $+0.02 \%(w / v) \mathrm{SiO}_{2}+0.02 \%(w / v) \mathrm{ZnO}$ \\
S8 & PE PANI $+0.01 \%(w / v) \mathrm{ZnO}$ \\
S9 & PE PANI $+0.02 \%(w / v) \mathrm{ZnO}$ \\
\hline
\end{tabular}

air dried and microscopic analysis were carried out. The biomass accumulated over the pre weighed cage net was recorded after air drying using an electronic balance with $0.001 \mathrm{~g}$ sensitivity. The difference in weight was used to calculate the accumulation in per $\mathrm{kg}$ of cage net. Due to the limited space in the test site, fearing the loss of uniformity in exposure (depth within 0.75-1.25 m), and need to expose the rack in length wise, prevented to incorporate more replicates in the experiment.

The surface characteristics of treated webbings were analyzed using Scanning electron microscope (SEM). The SEM micrographs of PE netting were recorded after sputtering with gold by using JEOL Model JSM-6390LV SEM. Fourier transform infrared (FTIR) spectra were obtained by using Thermo Nicolet Si10 FTIR. The materials were scanned from 650 to $4000 \mathrm{~cm}^{-1}$ at $4 \mathrm{~cm}^{-1}$ resolution was done by using zinc selenium Nicolet iTR accessory and to study the absorption in lower frequencies for identifying the inorganic part, another scan from 400 to $4000 \mathrm{~cm}^{-1}$ using FTIR fitted with microarray sampling accessory. The material was scanned 50 times and the average was showed as final plot. The data was processed using Omnic software available with the FTIR. The The images of nettings were examined through Leica MZ16A stereo microscope at $25 \mathrm{X}$ magnification.

\section{Results and discussion}

PE aquaculture cage net surface was modified by in situ synthesised PANI, and then nano $\mathrm{ZnO}-\mathrm{SiO}_{2}$ mixture were coated as described in materials and methods. Figure 1 and Table 2 presents the FTIR characteristics of PE-PANI, $\mathrm{SiO}_{2}$ treated PE-PANI (PE-PANI $\left.\mathrm{SiO}_{2}\right), \mathrm{SiO}_{2}$ and $\mathrm{ZnO}$ treated PE-PANI (PE-PANI $\mathrm{SiO}_{2}+\mathrm{ZnO}$ ), $\mathrm{ZnO}$ treated PE-PANI (PEPANI ZnO). The characteristic peaks of $P E$, shifted slightly after PANI and nano material treatments. Visible differences were obtained for the $\mathrm{CH}_{2}$ wagging and stretching band at 1176 and $2919 \mathrm{~cm}^{-1}$ respectively. PE-PANI $\mathrm{SiO}_{2}$
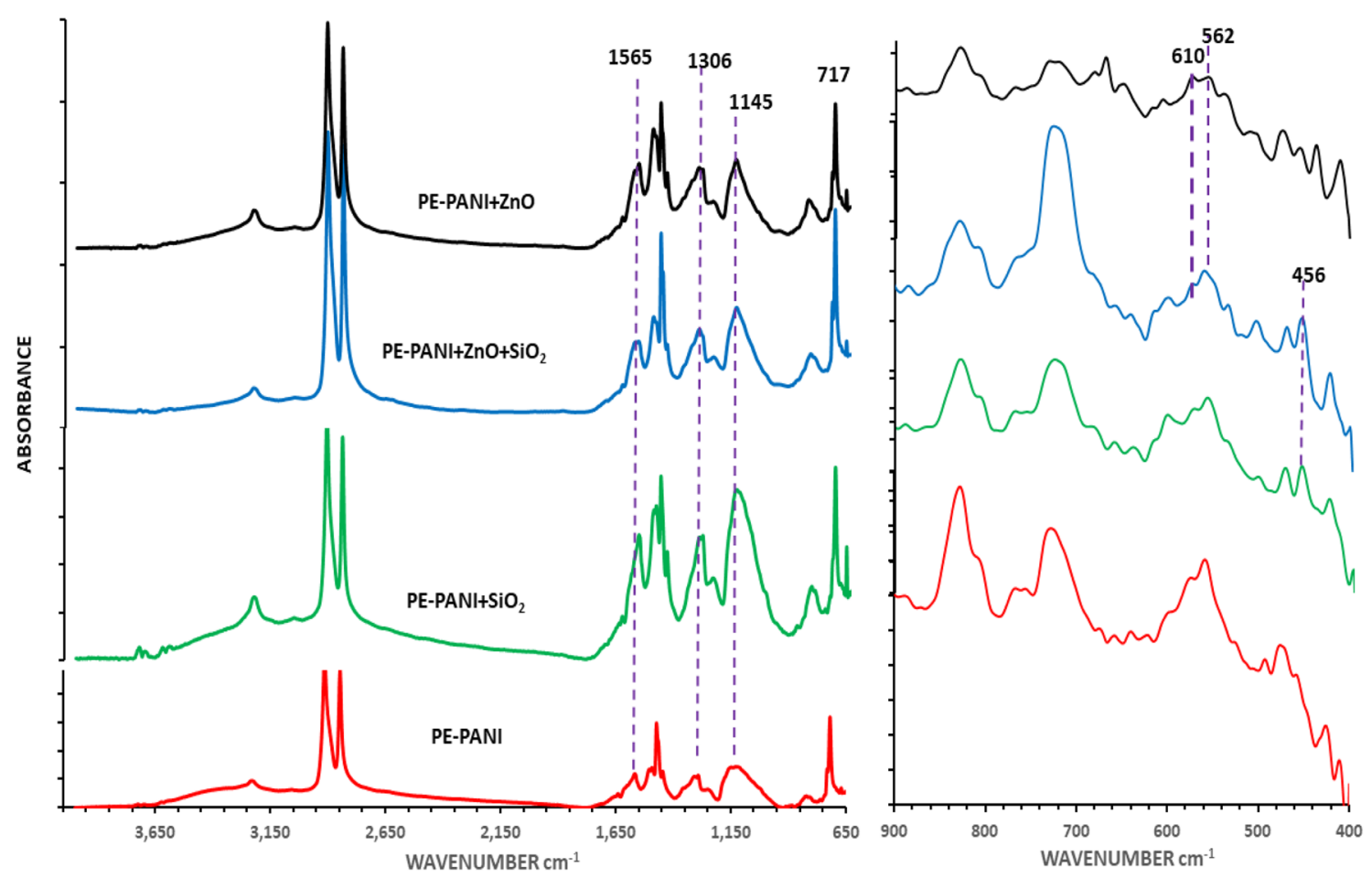

Fig. 1 FTIR spectra of PE-PANI, PE-PANI $+\mathrm{SiO}_{2}, \mathrm{PE}-\mathrm{PANI}+\mathrm{ZnO}$ and $\mathrm{PE}-\mathrm{PANI}+\mathrm{ZnO}+\mathrm{SiO}_{2}$. Major functional group indicated in the figure 
Table 2 FTIR characteristics of PE-PANI, PE-PANI SiO ${ }_{2}$, PE-PANI SiO ${ }_{2}+\mathrm{ZnO}_{2}$, PE-PANI ZnO

\begin{tabular}{|c|c|c|c|c|c|}
\hline \multirow{2}{*}{$\begin{array}{l}\text { Reported FTIR absorption in } \\
\text { literatures (wavenumber } \mathrm{cm}^{-1} \text { ) }\end{array}$} & \multicolumn{4}{|c|}{ FTIR absorption results in the study } & \multirow[t]{2}{*}{ Description } \\
\hline & PE-PANI & PE-PANI $\mathrm{SiO}_{2}$ & PE-PANI $\mathrm{SiO}_{2+} \mathrm{ZnO}$ & PE-PANI ZnO & \\
\hline \multicolumn{6}{|l|}{ Polyethylene [6] } \\
\hline 731,720 & 728,716 & 726,716 & 729,717 & 729,716 & $\mathrm{CH}_{2}$ rocking deformation \\
\hline 1176 & 1150 & 1143 & 1144 & 1145 & $\mathrm{CH}_{2}$ wagging deformation \\
\hline 1366 & 1361 & 1362 & 1365 & 1365 & $\mathrm{CH}_{2}$ wagging deformation \\
\hline 1463 & 1471 & 1471 & 1462 & 1471 & $\mathrm{CH}_{2}$ bending \\
\hline 2851 & 2847 & 2848 & 2846 & 2848 & $\mathrm{CH}_{2}$ symmetric \\
\hline 2919 & 2918 & 2913 & 2908 & 2911 & $\mathrm{CH}_{2}$ asymmetric \\
\hline \multicolumn{6}{|l|}{ Polyaniline [6] } \\
\hline 829 & 818 & 819 & 823 & 832 & $\mathrm{C}-\mathrm{H}$ str of Quinoid ring out of plane \\
\hline 1027 & 1017 & 1014 & 1012 & 1040 & Quinoid, $\mathrm{NH}^{4+}$ \\
\hline 1141 & 1154 & 1143 & 1144 & 1145 & $\begin{array}{l}\mathrm{C}-\mathrm{H} \text { str of Quinoid and benzenoid } \\
\text { Quinoid, } \mathrm{NH}^{+}\end{array}$ \\
\hline 1306 & 1306 & 1304 & 1305 & 1306 & $v(\mathrm{C}-\mathrm{N}) \mathrm{Sec}$ aromatic amine \\
\hline 1500 & 1502 & 1501 & 1503 & 1504 & $\mathrm{C}-\mathrm{C}$ str Benzenoid ring \\
\hline 1585 & 1565 & 1566 & 1568 & 1566 & $\mathrm{C}-\mathrm{C}$ bond of Quinoid ring \\
\hline \multicolumn{6}{|l|}{ Nano $\mathrm{ZnO}_{2}[24,25]$} \\
\hline 548 & & & 562 & 562 & $\mathrm{Zn}-\mathrm{O}$ stretching \\
\hline 620 & - & & 610 & 610 & $\mathrm{Zn}-\mathrm{O}$ deformation \\
\hline \multicolumn{6}{|l|}{$\mathrm{Nano} \mathrm{SiO}_{2}[26,27]$} \\
\hline 452 & - & 456 & 471 & - & $\mathrm{Si}-\mathrm{O}-\mathrm{Si}$ flexural libration vibration \\
\hline 950 & - & 953 & 960 & - & $\mathrm{Si}-\mathrm{OH}$ asymmetric vibration \\
\hline 1090 & - & 1083 & 1085 & - & Si-O asymmetric vibration \\
\hline
\end{tabular}

and PE-PANI ZnO exhibited a shift in peaks at 2908 and $2911 \mathrm{~cm}^{-1}$ respectively. Similarly PE-PANI $\mathrm{SiO}_{2}$ and PEPANI ZnO exhibited a shift in absorption from 1176 to $1143 \mathrm{~cm}^{-1}$. The shifting was due to the influence of PANI, $\mathrm{SiO}_{2}$ and $\mathrm{ZnO}$ in the polyethylene matrix.

The FTIR absorption characteristics of PANI changed after $\mathrm{ZnO}$ and $\mathrm{SiO}_{2}$ treatments. Quinoid and benzenoid ring vibrations at $1585 \mathrm{~cm}^{-1}$ shifted to the lower frequency at $\sim 1566 \mathrm{~cm}^{-1}$, indicating that $\mathrm{ZnO}$ and $\mathrm{SiO}_{2}$ were attached to the quinoid ring. Observed absorptions for $\mathrm{ZnO}$ stretching and $\mathrm{Zn}-\mathrm{O}$ deformation were 548 [24] and $620 \mathrm{~cm}^{-1}$ [25] respectively, and the similar results were obtained at 562 and $610 \mathrm{~cm}^{-1}$ respectively, which indicated the interaction of $\mathrm{ZnO}$ with PANI. All the three characteristic peaks of $\mathrm{SiO}_{2}$ were obtained in the spectra of the $\mathrm{SiO}_{2}$ treated matrix. A shift appeared in the infrared absorption of $\mathrm{SiO}_{2}$ mainly due to the influence of PANI and nano particles. The results revealed that both the metal oxides interacted strongly with the quinoid ring of PANI in the matrix.

SEM micrographs of PE, PE-PANI, and PE-PANI with metal oxides are presented in Fig. 2. The micrographs indicated that strong interaction of PANI nano rods formed on the PE matirx with PE and the former uniformly coated on the surface. $\mathrm{SiO}_{2}$ particles attached onto PANI nano rods were visible. $\mathrm{SiO}_{2}$ particles were distributed uniformly in the matrix. The matrix treated with the mixture of $\mathrm{ZnO}$ and $\mathrm{SiO}_{2}$ exhibited a uniformly distributed coating. The netting with equal concentration of $\mathrm{ZnO}-\mathrm{SiO}_{2}$ coating treatment exhibited a different pattern. The $\mathrm{ZnO}$ coating on PANI exhibited an uniform distribution of $\mathrm{ZnO}$ flakes which was visible.

\subsection{Field studies}

The treated aquaculture cage nets PE-PANI, PE-PANI $\mathrm{SiO}_{2}$, PE-PANI $\mathrm{SiO}_{2}+\mathrm{ZnO}$ and PE-PANI $\mathrm{ZnO}$ were subjected to the estuarine environment for three months and retrieved after first, second and third month for their performance evaluation (Fig. 3). Fouling accumulated on aquaculture cage nets of different treatments after various periods were illustrated in Fig. 3. On most samples retrieved after 1 month, showed numerous foulers were attached. The samples retrieved after second and third month exhibited uneven fouling pattern. The $0.01 \%(\mathrm{w} / \mathrm{v})$ each of nano $\mathrm{ZnO}$ and $\mathrm{SiO}_{2}$ treated net (S4) sample retrieved after second and third month exhibited the lowest biofouling. The accumulation pattern of fouling organism was different in $\mathrm{ZnO}+\mathrm{SiO}_{2}$ treated samples. Studies have reported that the fouling diversity in the Cochin estuary varied with seasons [28]. The biomass accumulation observed after 
Fig. 2 Scanning Electron Micrographs of PE, PE-PANI, $\mathrm{PE}-\mathrm{PANI}+0.02 \% \mathrm{SiO}_{2}(\mathrm{~S} 3)$, $\mathrm{PE}-\mathrm{PANI}+0.02 \% \mathrm{SiO}_{2}+0.01 \%$ $\mathrm{ZnO}(\mathrm{S} 5), \mathrm{PE}-\mathrm{PANI}+0.02 \%$ $\mathrm{SiO}_{2}+0.02 \% \mathrm{ZnO}(\mathrm{S} 7)$, PE$\mathrm{PANI}+0.02 \% \mathrm{ZnO}(\mathrm{S} 9)$

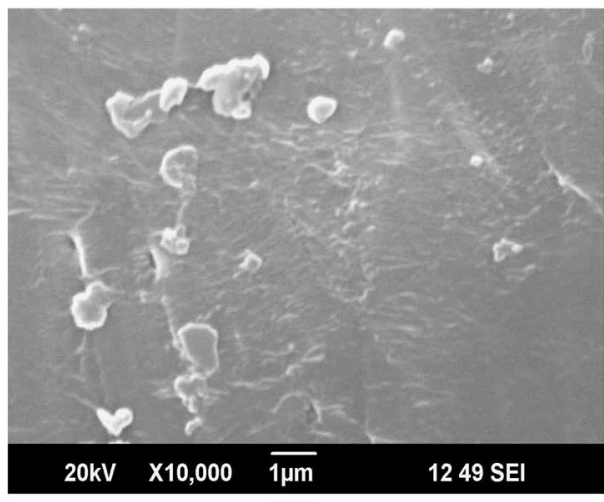

PE

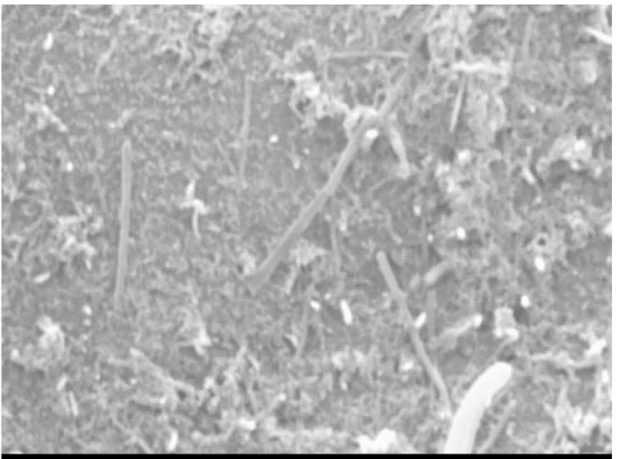

$20 k V \quad \times 10,000 \quad \overline{1 \mu m}$

S3

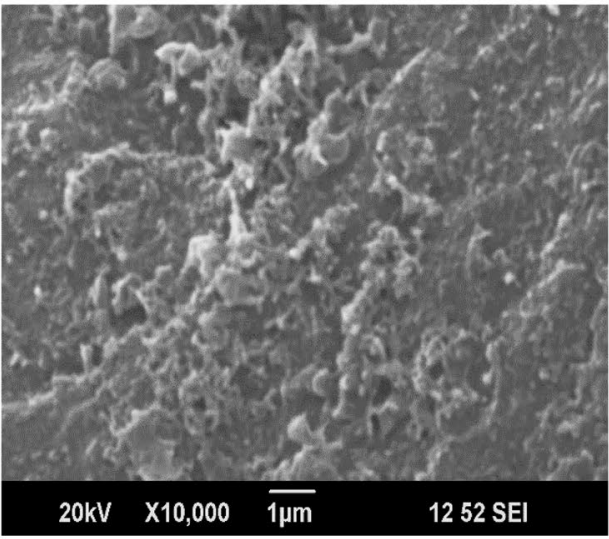

S7
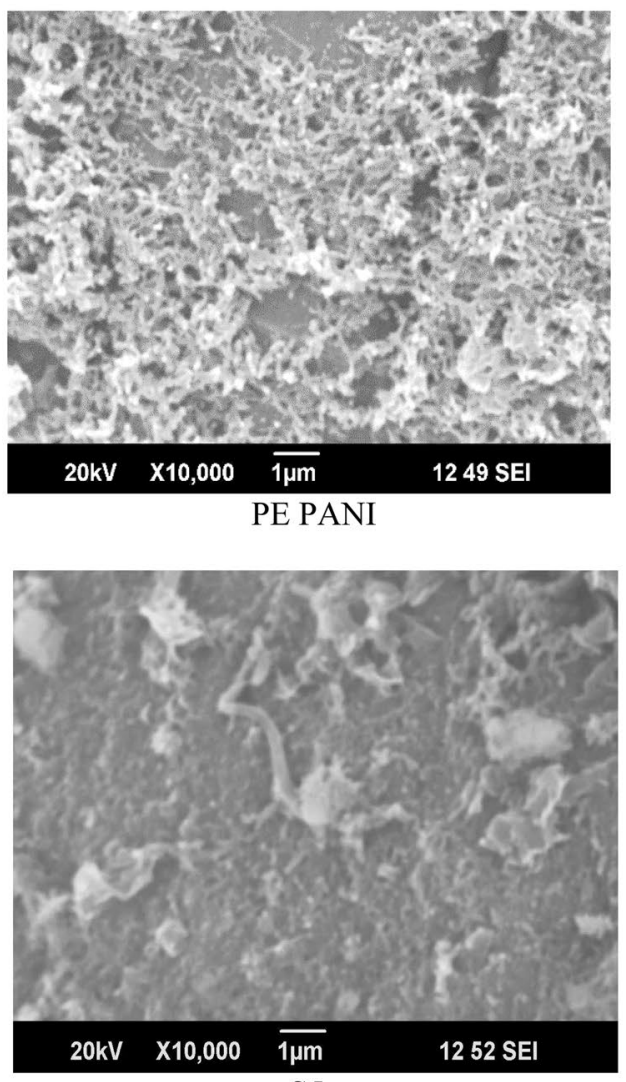

S5

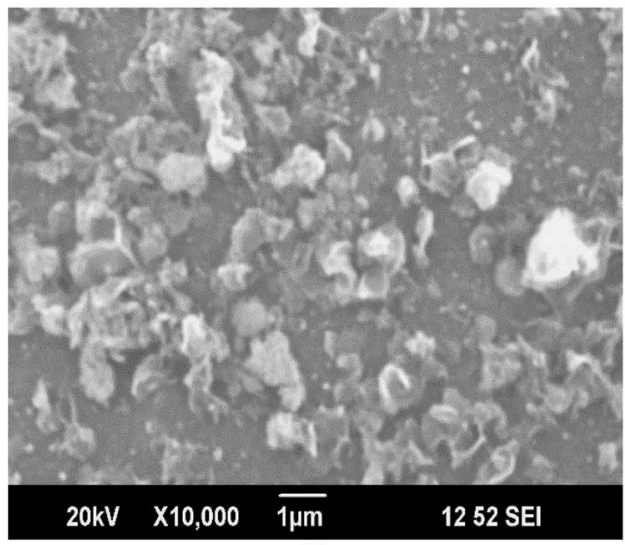

S9 different treatments were shown in Fig. 4. The results did not provide any definite pattern for biofouling accumulation. Variations in the first, second and third months probably occurred due to climate change experienced at exposure sites during that perod. Field experimental environments undergo unusual variations which researchers could not have controlled. Microscopic images and biomass evaluation revealed that the nets treated with $0.01 \%(\mathrm{w} / \mathrm{v})$ of nano $\mathrm{ZnO}$ and $\mathrm{SiO}_{2}$ exhibited the highest biofouling resistance and nano $\mathrm{ZnO}$ and $\mathrm{SiO}_{2}$ acted synergistically to inhibit biofoulers accumulation on the net.
On examining biomass accumulation on the nets treated with 0.01 and $0.02 \%(\mathrm{w} / \mathrm{v}) \mathrm{SiO}_{2}$, exhibited increased fouling biomass accumulation than control upto 2 months (Fig. 4). This finding indicated that in the PANI, $\mathrm{PE}-\mathrm{PANI}+\mathrm{SiO}_{2}(\mathrm{~S} 2$ and S3) can encourage foulers attachment, where as 0.01 and $0.02 \%(\mathrm{w} / \mathrm{v}) \mathrm{PE}-\mathrm{PANI}+\mathrm{ZnO}$ (S8 and S9) treated net exhibited comparatively low biomass accumulation because of the antifouling property of nano $\mathrm{ZnO}$. The $\mathrm{PE}-\mathrm{PANI}+\mathrm{ZnO}+\mathrm{SiO}_{2}$ treatment (S4 to $\mathrm{S} 7$ ) reduced the accumulation of fouling biomass. Figure 4 revealed that the three month sample exhibited lower accumulation 
Fig. 3 Microscopic images of the aquaculture cage nets SO-S9 exposed in estuary for 3 months. The 3rd month image file of $\mathrm{S} 9$ was corrupted hence could not be included here
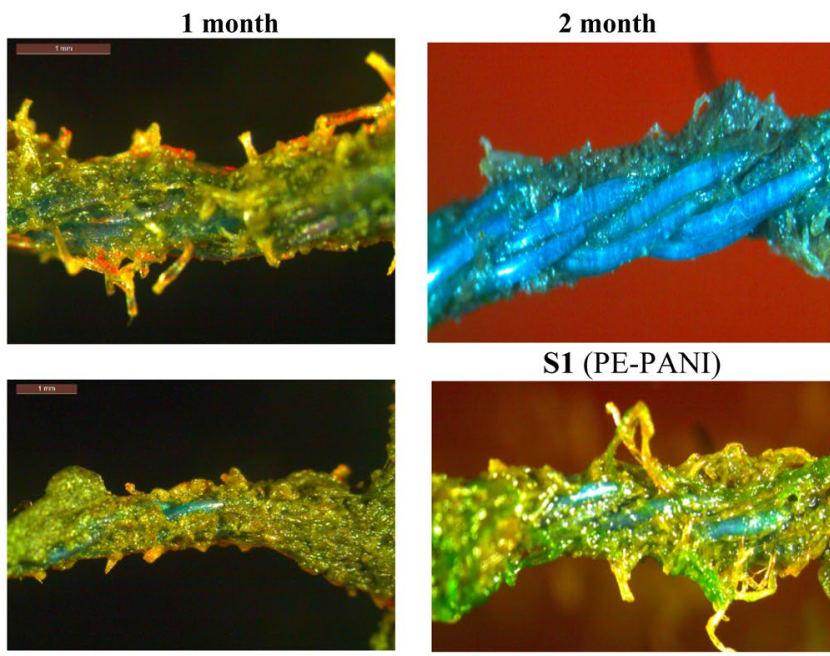

S1 (PE-PANI)
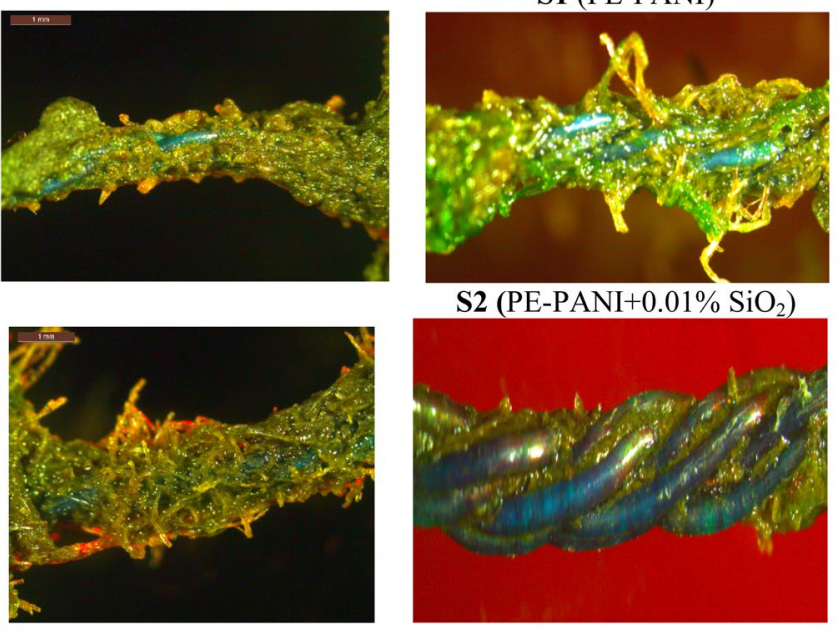

S3 (PE-PANI $+0.02 \% \mathrm{SiO}_{2}$ )
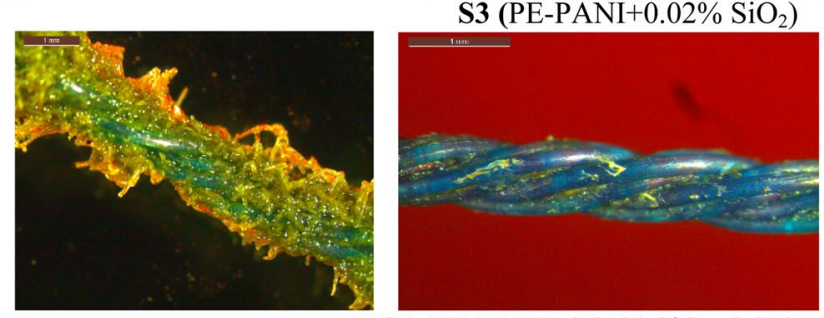

S4 (PE-PANI $\left.+0.01 \% \mathrm{SiO}_{2}+0.01 \% \mathrm{ZnO}\right)$
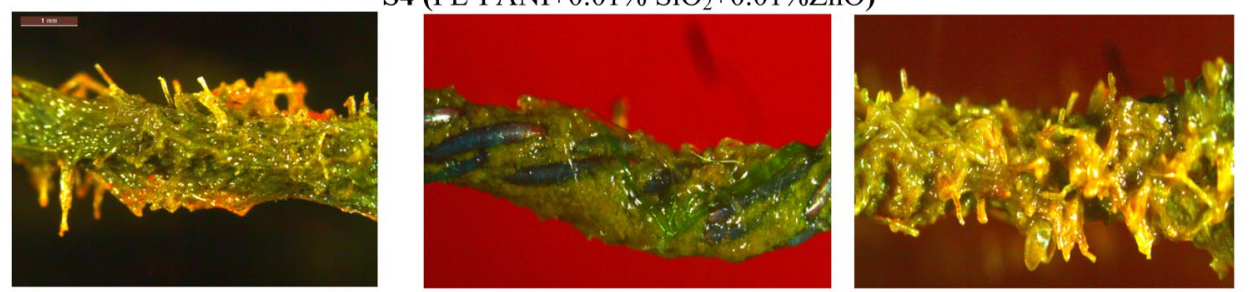

S5 (PE-PANI $\left.+0.02 \% \mathrm{SiO}_{2}+0.01 \% \mathrm{ZnO}\right)$

Nano $\mathrm{ZnO}$ is a known antimicrobial oxide and attacks the microroganisms by synthesising reactive oxygen species [29]. An incident UV light causes interfacial movement of electrons in oxygen and zinc vacancies, which leads to the formation electrons and holes in the conduction and valence bands, respectively [30, 31]. Holes react with the water molecules attached to $\mathrm{ZnO}$ and form hydroxyl radical $\left(\mathrm{OH}^{\circ}\right)$. Montazer and Amiri [17] described the reaction mechanism of this process in detail. It has already demonstrated that the biocidal activity of $\mathrm{OH}^{\circ}$, and it is adequate to kill the microbes present in the biofilms, fungi and phytoplankton [32]. A high photocatalytic activity of $\mathrm{ZnO}$ depends on the 
Fig. 3 (continued)
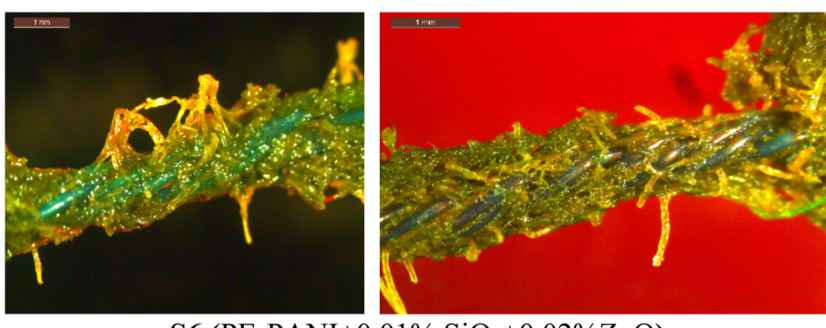

S6 (PE-PANI $\left.+0.01 \% \mathrm{SiO}_{2}+0.02 \% \mathrm{ZnO}\right)$
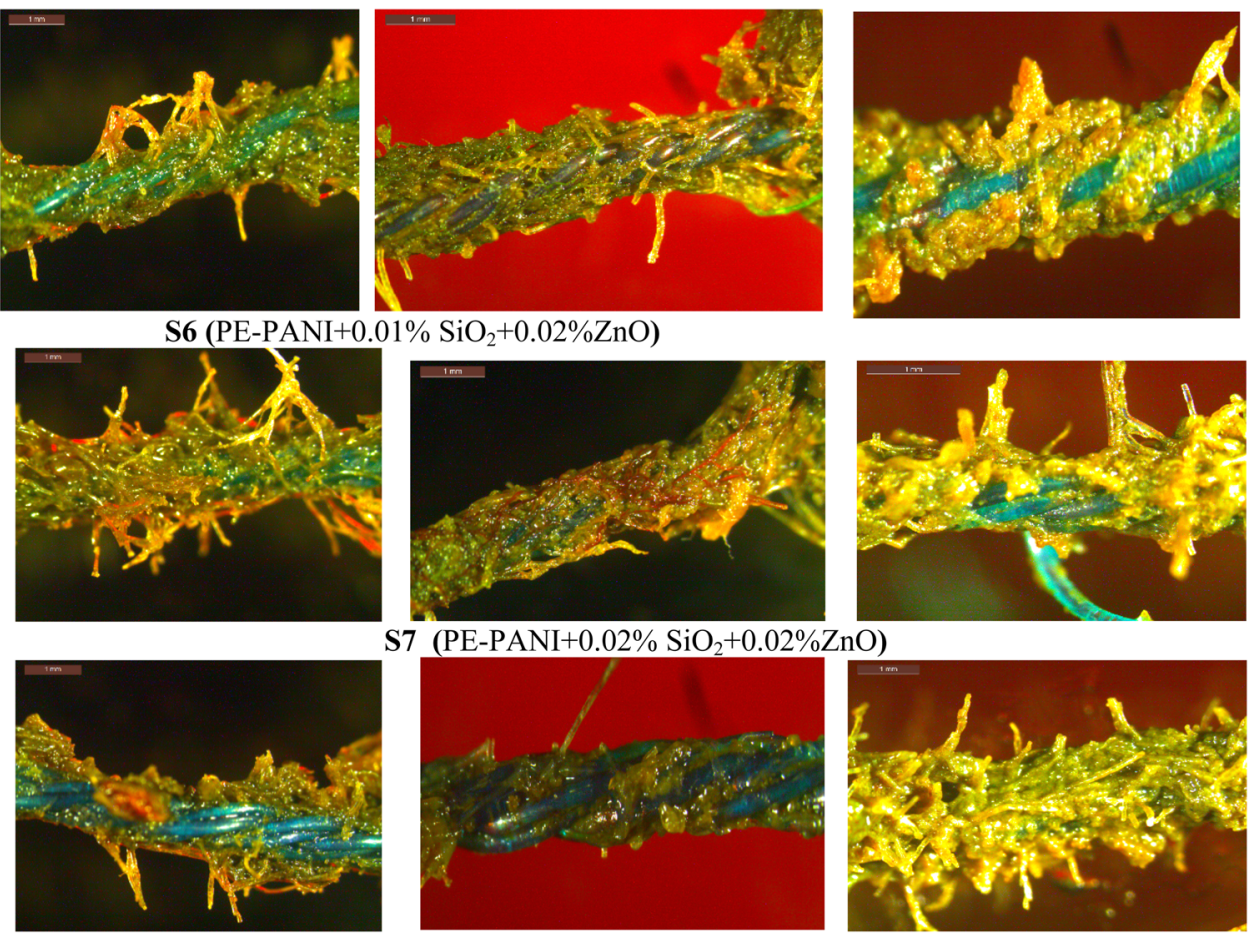

S7 (PE-PANI+0.02\% $\left.\mathrm{SiO}_{2}+0.02 \% \mathrm{ZnO}\right)$
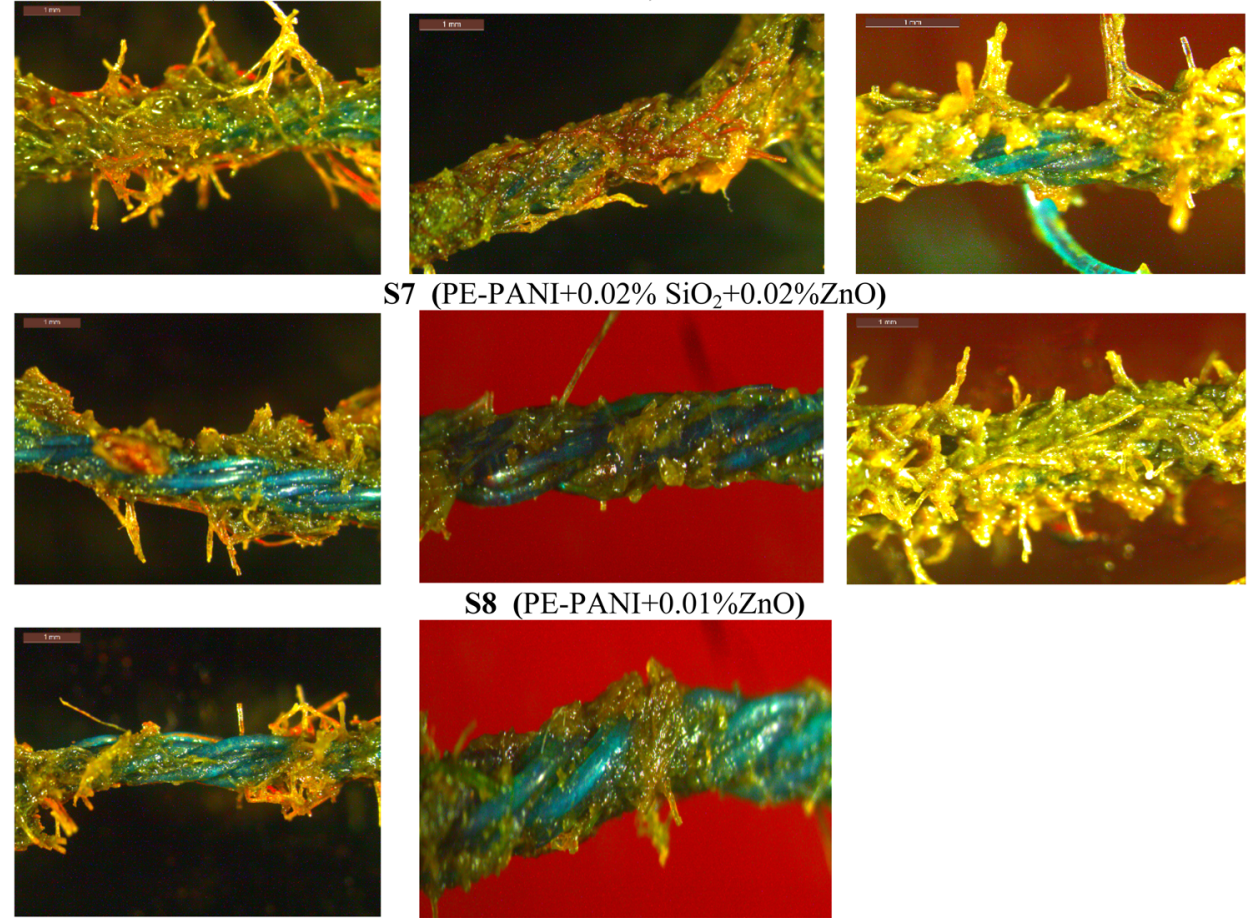

S8 (PE-PANI $+0.01 \% \mathrm{ZnO})$
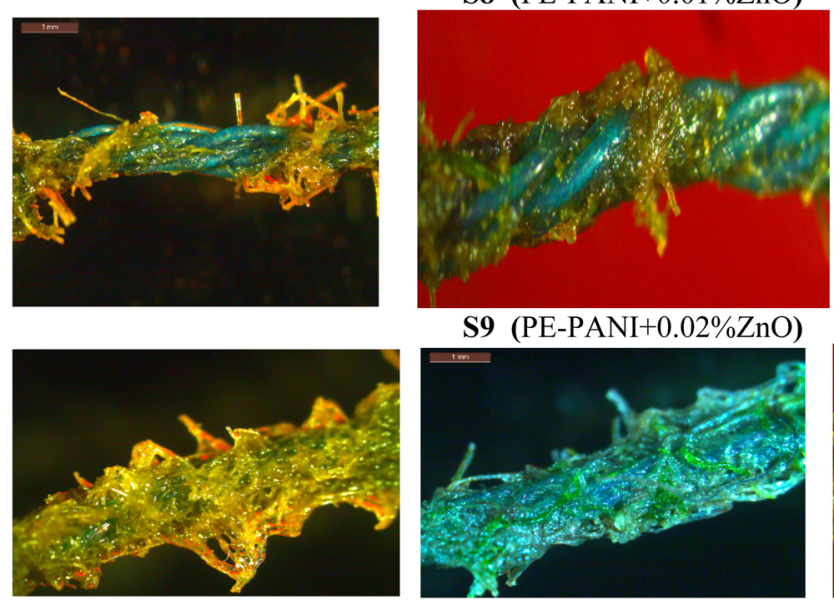

S9 (PE-PANI $+0.02 \% \mathrm{ZnO})$
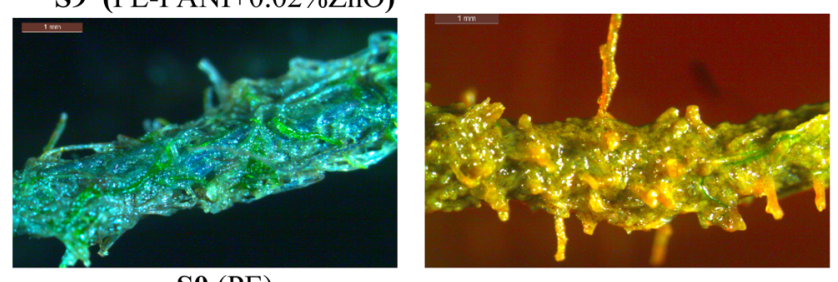

S0 (PE)

Fig. 4 Biomass accumulation in cage nets retrieved after first, second and third months

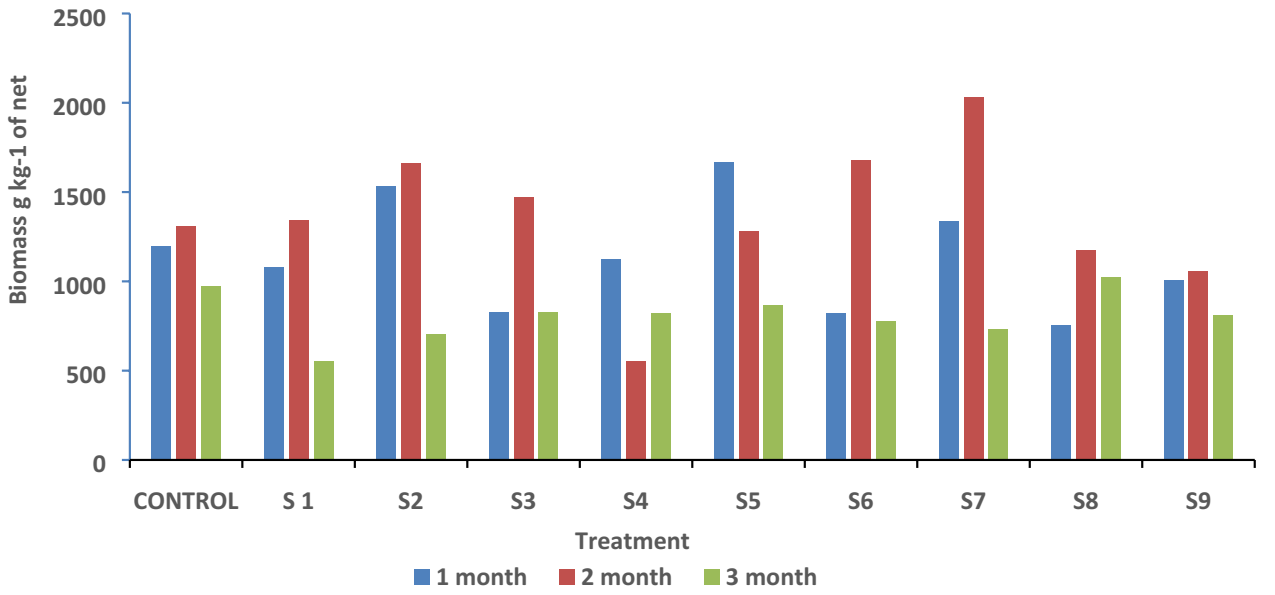

SN Applied Sciences

A SPRINGER NATURE journa 
number of active sites. Studies by Lee et al. [18] predicted that UV radiation penetrates upto $10 \%$ of the euphotic depth of oligotrophic waters. The concentration of UV light may be low compared to the visible radiations in an aquatic system. Thus band gap reduction is necessary to activate $\mathrm{ZnO}$ under visible light. Electron rich particles like chemically reduced graphene, carbon nanotubes and the nano composites of semiconductors, were employed to reduce the band gap [19-23]. In the present study the electron rich conductng polymer, PANI, was used as the substrate to coat the oxides. The nano $\mathrm{ZnO}$ was strongly adsorbed over PANI and this might have reduced the band gap of $\mathrm{ZnO}$ and hence increased the photocatalytic effect $[23,33]$. Mao et al. [34] reported the synergistic effect of nano $\mathrm{ZnO}$ and $\mathrm{SiO}_{2}$ to block the UV radiation in cotton fibres. In the present study, the $\mathrm{SiO}_{2}$ might have influenced synergistically with $\mathrm{ZnO}$ to inhibit biofouling. In presence of PANI and $\mathrm{SiO}_{2}$ the $\mathrm{e}^{-} / \mathrm{h}^{+}$recombination rate of $\mathrm{ZnO}$ increased and this might have resulted increased photocatalytic effect and biofouling resistance [35-37]. This finding was correlated with the results of bioaccumulation pattern of nano $\mathrm{SiO}_{2}$ and $\mathrm{ZnO}$ coated cage net. Increased bioaccumulation was showed in $\mathrm{SiO}_{2}$ coated net than $\mathrm{ZnO}$ coated net, where as PANI-ZnO- $\mathrm{SiO}_{2}$ system exhibited more efficient biofouling resistance.

\section{Conclusion}

Biofouling is a serious problem in aquacutlture because resolving it utilizes one fourth of total project expenses. PE is a non polar molecule commonly used for aquaculture cage nets and is highly demanded for coating antifouling biocides directly over it. This study reported the applications of nano silicon and zinc oxides with PANI coated on PE to prevent biofouling in the aquatic environment. The suface morphology analysis confirmed the formation of nano zinc and silicon oxides on PE -PANI. The results obtained from field exposure experiments revealed that treating PE-PANI net with $0.01 \%(\mathrm{w} / \mathrm{v})$ each of the nano $\mathrm{ZnO}$ and $\mathrm{SiO}_{2}$ provided highest biofouling resistance and the nano $\mathrm{ZnO}$ and $\mathrm{SiO}_{2}$ acted synergistically to inhibit biofoulers accumulation on PE net. The results must be assessed further through extensive field exposures in aquaculture farms.

Acknowledgements The authors thank the Director of ICAR Central Institute of Fisheries Technology for providing facilities, the technical staff of the Fishing Technology Division of ICAR-CIFT, STIC, CUSAT for extending SEM facilities and Head Microbiology Division of ICAR CIFT for providing FTIR facilities. Thanks to Editing India for English correction of the manuscript.
Author contributions Experiments were designed by P.M.A, S.N.T, L.E and N.M.L. Experiments performed by N.M.L, PMA and A.K.K. Manuscript written by N.M.L and P.M.A

Data availablity The data pertaining to this research paper is available with the corresponding author and will be shared the same after a reasonable request.

\section{Compliance with ethical standard}

Conflict of interest The authors declare that they have no Conflict of interest.

\section{References}

1. Armstrong E, Boyd KG, Pisacane A, Peppiatt CJ, Burgess JG (2000) Marine microbial natural products in antifouling coatings. Biofouling 16(2-4):215-224. https://doi.org/10.1080/0892701000 9378446

2. Fitridge I, Dempster T, Guenther J, De Nys R (2012) The impact and control of biofouling in marine aquaculture: a review. Biofouling 28(7):649-669

3. Braithwaite RA, McEvoy LA (2005) Marine biofouling on fish farms and its remediation. Adv Mar Biol 47:215-252

4. Lewis JA (1998) Marine biofouling and its prevention. Mater Forum 22:41-46

5. Ashraf PM, Sasikala KG, Thomas SN, Edwin L (2020) Biofouling resistant polyethylene cage aquaculture nettings: a new approach using polyaniline and nano copper oxide. Arab J Chem 13:875-882. https://doi.org/10.1016/j.arabjc.2017.08.006

6. Chen S, Zhu J, Zhou T, He B, Huang W, Wang B (2012) Preparation and properties study of polyaniline conductive anti-fouling coatings. Int J Electrochem Sci 7(9):8170

7. Mohan A, Ashraf PM (2019) Biofouling Control using nano silicon dioxide reinforced mixed-charged zwitterionic hydrogel in aquaculture cage nets. Langmuir 35(12):4328-4335

8. Knowles BR, Wagner P, Maclaughlin S, Higgins MJ, Molino PJ (2017) Silica nanoparticles functionalized with zwitterionic sulfobetaine siloxane for application as a versatile antifouling coating system. ACS Appl Mater Interfaces 9(22):18584-18594

9. Dong A, Huang J, Lan S, Wang T, Xiao L, Wang W, Zhao T, Zheng X, Liu F, Gao G, Chen Y (2011) Synthesis of N-halamine-functionalized silica-polymer core-shell nanoparticles and their enhanced antibacterial activity. Nanotechnology 22(29):295602

10. Nguyen Ai T, Baggerman J, Paulusse JMJ, van Rijn CJM, Zuilhof $H$ (2011) Stable protein-repellent zwitterionic polymer brushes grafted from silicon nitride. Langmuir 27(6):2587-2594

11. Serrano MB, Despas C, Herzog G, Walcarius A (2015) Mesoporous silica thin films for molecular sieving and electrode surface protection against biofouling. Electrochem Commun 52:34-36

12. Al-Naamani L, Dobretsov S, Dutta J, Burgess JG (2017) Chitosanzinc oxide nanocomposite coatings for the prevention of marine biofouling. Chemosphere 168:408-417

13. Zhang J, Pu G, Severtson SJ (2010) Fabrication of Zinc oxide/ polydimethylsiloxane composite surfaces demonstrating oilfouling-resistant superhydrophobicity. ACS Appl Mater Interfaces 2(10):2880-2883

14. Rajabi H, Ghaemi N, Madaeni SS, Daraei P, Astinchap B, Zinadini S, Razavizadeh SH (2015) Nano-ZnO embedded mixed matrix polyethersulfone (PES) membrane: influence of nanofiller shape on characterization and fouling resistance. Appl Surf Sci 349:66-77 
15. Chung YT, Ba-Abbad MM, Mohammad AW, Benamor A (2016) Functionalization of zinc oxide $(\mathrm{ZnO})$ nanoparticles and its effects on polysulfone-ZnO membranes. Desalin Water Treat 57(17):7801-7811

16. Ashraf PM, Anuradha R (2018) Corrosion resistance of BIS 2062grade steel coated with nano-metal-oxide mixtures of iron, cerium, and titanium in the marine environment. Appl Nanosci $8(1-2): 41-51$

17. Montazer M, Amiri MM (2014) ZnO nano reactor on textiles and polymers: ex situ and in situ synthesis, application, and characterization. J Phys Chem B 118:1453-1470

18. Lee Z, Hu C, Shang S, Du K, Lewis M, Arnone R, Brewin R (2013) Penetration of UV-visible solar radiation in the global oceans: insights from ocean color remote sensing. J Geophys Res Oceans 118:4241-4255. https://doi.org/10.1002/jgrc.20308

19. Zhang $Y$, Tang ZR, Fu X, Xu YJ (2011) Engineering the unique $2 D$ mat of graphene to achieve graphene-TiO2 nanocomposite for photocatalytic selective transformation: what advantage does graphene have over its forebear carbon nanotube? ACS Nano 5(9):7426-7435

20. Zhang Y, Tang ZR, Fu X, Xu YJ (2010) TiO2_graphene nanocomposites for gas-phase photocatalytic degradation of volatile aromatic pollutant: is $\mathrm{TiO}_{2}$ graphene truly different from other TiO2_carbon composite materials? ACS Nano 4:7303-7314

21. Zhang Y, Zhang N, Tang ZR, Xu YJ (2012) Graphene transforms wide band gap ZnS to a visible light photocatalyst. the new role of graphene as a macromolecular photosensitizer. ACS Nano 6:9777-9789

22. Zhang N, Zhang Y, Xu YJ (2012) Recent progress on graphenebased photocatalysts: current status and future perspectives. Nanoscale 4:5792-5813

23. Chen Z, Zhang N, Xu YJ (2013) Synthesis of graphene-ZnO nanorod nanocomposites with improved photocatalytic and anti- photocorrosion. Cryst Eng Comm 15:3022-3030

24. Zhu Y, Apostoluk A, Gautier P, Valette A, Omar L, Cornier T, Bluet JM, Masenelli-Varlot K, Daniele S, Masenelli B (2016) Intense visible emission from $\mathrm{ZnO} / \mathrm{PAAX}(\mathrm{X}=\mathrm{H}$ or $\mathrm{Na}$ ) nanocomposite synthesized via a simple and scalable sol-gel method. Sci Rep 6:23557

25. Kumar H, Rani R (2013) Structural and optical characterization of $\mathrm{ZnO}$ nanoparticles synthesized by microemulsion route. Int Lett Chem Phys Astron 14:26-36. https://doi.org/10.18052/ www.scipress.com/ILCPA.19.26
26. Beganskienė $A$, Sirutkaitis $V$, Kurtinaitienè $M$, Juškènas $R$, Kareiva A (2004) FTIR, TEM and NMR investigations of Stöber silica nanoparticles. Mater Sci (Medžiagotyra) 10:287-290

27. Tang X, Alavi S, Herald TJ (2008) Effects of plasticizers on the structure and properties of starch-clay nanocomposite films. Carbohydr Polym 74(3):552-558

28. Geetha PN, Nandan SB (2014) Ecology, diversity, and abundance of macrobenthic crustaceans in Cochin Estuary, India. Res J Recent Sci 3:137-148

29. Sharma D, Rajput J, Kaith BS, Kaur M, Sharma S (2010) Synthesis of $\mathrm{ZnO}$ Nanoparticles and study of their antibacterial and antifungal properties. Thin Sol Films 519:1224-1229

30. Yatmaz HC, Akyol A, Bayramoglu M (2004) Kinetics of the photocatalytic decolorization of an azo reactive dye in aqueous $\mathrm{ZnO}$ suspensions. Ind Eng Chem Res 43:6035-6039

31. Nair G, Nirmala M, Rekha K, Anukaliani A (2011) Structural, optical, photo catalytic and antibacterial activity of $\mathrm{ZnO}$ and Co doped ZnO nanoparticles. J Mater Lett 65:1797-1800

32. Van Dijken A, Meulenkamp EA, Vanmaekelbergh D, Meijerink A (2000) The kinetics of the radiative and nonradiative processes in nanocrystalline $\mathrm{ZnO}$ particles upon photoexcitation. J Phys Chem B 104:1715-1723

33. Zhang Y, Chen Z, Liu S, Xu YJ (2013) Size effect induced activity enhancement and anti-photocorrosion of reduced graphene Oxide/ZnO composites for degradation of organic dyes and reduction of $\mathrm{Cr}(\mathrm{VI})$ in water. Appl Catal B 140-141:598-607

34. Mao ZP, Shi QP, Zhang LP, Cao HT (2009) The formation and UVblocking property of needle-shaped $\mathrm{ZnO}$ nanorod on cotton fabric. Thin Sol Films 57:2681-2686

35. Zhou M, Yu J, Cheng B (2006) Effects of Fe-doping on the photocatalytic activity of mesoporous $\mathrm{TiO}_{2}$ powders prepared by an ultrasonic method. J Hazard Mater 137(3):1838-1847

36. Klingshirn CF (2007) ZnO: material, physics and applications. ChemPhysChem 8:782-803

37. Estrellan CR, Salim C, Hinode H (2009) Photocatalytic activity of sol-gel derived $\mathrm{TiO}_{2}$ co-doped with iron and niobium. React Kinet Catal Lett 98:187-192

Publisher's Note Springer Nature remains neutral with regard to jurisdictional claims in published maps and institutional affiliations. 